\begin{tabular}{|l|l|l|}
\hline T. & Tomohiko & Kusuhara $^{\text {a }}$ \\
\hline M. & Mitsuyoshi & Ayabe $^{\mathrm{a}}$ \\
\hline H. & Hidetada & Hino $^{\mathrm{a}}$ \\
\hline H. & Hiroshi & Shoji $^{\mathrm{a}}$ \\
\hline S. & Shigeto & Yamada $^{\mathrm{b}}$ \\
\hline
\end{tabular}

${ }^{\mathrm{a}}$ First Department (Neurology) of Internal Medicine, Kurume University School of Medicine, and ${ }^{\mathrm{b}}$ Institute of Brain Diseases, Kurume University School of Medicine, Kurume, Japan

\title{
Cerebrospinal Fluid Levels of Monoamines in Patients with Japanese Encephalitis
}

\section{H. Shoji, MD, First Department (Neurology) of Internal Medicine, Kurume University School of Medicine, Asahimachi 67, Kurume, 830 (Japan)}

In Japanese encephalitis (JE), extrapyramidal signs such as tremor and rigidity are often observed from the acute stage to recovery. Sometimes, persistent parkinsonism following JE has been reported [1,2], Changes in monoamine level in cerebrospinal fluid (CSF) have been described in viral encephalitis only in animal models [3, 4]. We report on monoamine metabolism in CSF in 11 patients with JE.

Homovanillic acid (HVA) and 5-hydroxyindoleacetic acid (5-HIAA) were analyzed between 1988 and 1993 in CSF from 11 Japanese patients with JE. There were 7 males and 4 females; aged 57.4 \pm 12.4 years (mean age \pm SD). All patients showed at least a fourfold rise in titer on the complement fixation or hemagglutination inhibition test for JE virus confirmed in paired sera or CSF. Levels of HVA and 5-HIAA in CSF were assayed in 11 patients who were mainly in the subacute stage of the disease, i.e. $14-40$ days after onset. In 3 patients, specimens of CSF were also assayed at the acute stage, within 14 days after onset, and at the chronic stage after 40 days of onset. Samples of CSF from 10 patients with diabetic neuropathy were used as controls. There were 5 males and 5 females; aged $55.7 \pm 7.7$ years (mean \pm SD). CSF was taken in the morning after patients had rested for $2 \mathrm{~h}$.

Specimens of CSF were ultracentrifuged for $5 \mathrm{~min}$ at $15,000 \mathrm{~g}$, and HVA and 5-HIAA were determined in 20 ul of the supernatant by high-performance liquid chromatography. Data are presented as means \pm SD The statistical method used was Student's $t$ test, $p$ values of less than 0.05 were considered significant.

Clinical Data. Eleven patients developed JE between the middle of August to the beginning of September. Between the acute stage of the infection to recovery, several patients showed hemiplegia (4 patients), convulsions (3), parkinsonism (2) and impairment of memory (1), together with impaired consciousness and meningeal signs. Except for 2 patients, magnetic resonance imaging revealed abnormalities in the basal ganglia including the thalamus and brainstem. Four patients died of complications within 4-6 months after disease onset. Five patients showed no sequelae, while 2 patients had persistent parkinsonism and dementia.

CSF Levels of HVA and 5-HIAA (fig. 1). In the subacute stage of JE, the mean level of HVA in CSF was $11.99 \pm 4.72 \mathrm{ng} / \mathrm{ml}$ in the patients vs. $34.36 \pm 7.53 \mathrm{ng} / \mathrm{ml}$ in the controls. The mean level of 5-HIAA in CSF in the patients was $12.77 \pm 9.19 \mathrm{ng} / \mathrm{ml}$ vs. $27.73 \pm 8.59 \mathrm{ng} / \mathrm{ml}$ in the controls. CSF levels of HVA and 5-HIAA were significantly decreased in the patients as compared with the controls ( $\mathrm{p}<0.01$ ). No significant change was observed in the acute or chronic stage, but the number of patients in these stages was small. A decrease in HVA or 5-HIAA in CSF was not correlated with the outcome or the severity of sequelae, except in 2 patients with symptoms of parkinsonism consisting of akinesia, rigidity or tremor.

We previously found levodopa to be effective in treating patients with JE [unpubl. data, 1992]. This observation may be compatible with the decrease in CSF HVA in the subacute stage observed in the present study.

\section{6}

\section{5 - HIAA}


Fig. 1. Concentration of HVA and 5-HIAA in cerebrospinal fluid (CSF). HVA and 5-HIAA were significantly decreased in the CSF in the subacute stage of JE as compared with controls ( $\mathrm{p}<0.01)$. $\mathrm{O}=\mathrm{CSF}$ values in 2 patients with parkinsonism.

Yamashita et al. [4] studied the metabolism of monoamines in mice infected with JE virus and reported a decrease in dopamine and HVA concentrations in the cerebral cortex and diencephalon, while there was an increase in 5-HIAA. However, an increase in HVA or dopamine was found in rabbits infected with herpes simplex virus, probably due to impairment of the mesencephalic dopamine autore-ceptor, and the animals exhibited rotational behavior [5]. The monoamines and related metabolism in CSF in patients with JE and herpes simplex encephalitis should be further studied.

\section{References}

1 Shoji H, Hiraki Y, Kuwasaki N, Toyomasu T, Kaji M, Okudera T: Japanese encephalitis in the Kurume region of Japan: CT and MRI findings. J Neurol 1989;236:255-259.

2 Shoji H, Watanabe M, Itoh S, Kuwahara H, Hattori F: Japanese encephalitis and parkinsonism. J Neurol 1993;240:59-60.

3 Neeley SP, Cross AJ, Crow TJ, Johnson JA, Taylor GR: Herpes simplex virus encephalitis. Neuroanatomical and neurochemical selectivity. J Neurol Sci 1985;71:325-337.

4 Yamashita Y, Ito T, Hashimoto I, Ohyama A, Kuriyama K: Changes in cerebral level of monoamines by Japanese encephalitis virus infection (in Japanese). Virus 1989;39:47-54.

5 Paivarinta MA, Marttila RJ, Rinne JO, Rinne UK: Decrease in mesencephalic dopamine autoreceptors in experimental herpes simplex encephalitis. J Neural Transm 1992;89:71-80. 